\title{
A VISITA DOMICILIAR NA ESTRATÉGIA SAÚDE DA FAMÍLIA: PERCEPÇÃO DE ENFERMEIROS
}

Edirlei Machado dos Santos ${ }^{1}$, Sandra Helena Gomes Morais ${ }^{2}$

\begin{abstract}
RESUMO: A visita domiciliar é, atualmente, um instrumento essencial para a prática das ações no nível primário de assistência a saúde, em especial, na Estratégia Saúde da Família. Trata-se de um estudo descritivo e exploratório, de abordagem qualitativa, cujo objetivo foi identificar e analisar a percepção de enfermeiros acerca da visita domiciliar. Para a análise dos dados utilizou-se a técnica da Análise Temática. Foram identificadas duas unidades temáticas: $A$ visita domiciliar como possibilidade de criação de vínculo e $A$ visita domiciliar como possibilidade de uma assistência integral. Assim, a visita domiciliar como instrumento do processo de trabalho em saúde, em especial, na Atenção Primária à Saúde, se constitui num elemento facilitador para o acesso por parte dos usuários aos serviços públicos de saúde e se apresenta como uma forma integral de assistir, em que as reais necessidades de cada indivíduo/família podem ser identificadas. PALAVRAS-CHAVE: Visita domiciliar; Assistência domiciliar; Enfermagem em saúde pública.
\end{abstract}

\section{HOME VISITING IN THE FAMILY HEALTH STRATEGY: ITS PERCEPTION AMONG NURSES}

ABSTRACT: Currently, home visiting is an essential instrument for the practice of primary health actions, especially lined with the Family Health Strategy. This descriptive and exploratory study with a qualitative approach aims to identify and analyze how nurses perceive home visiting. Thematic analysis was used to analyse the data. Two thematic unities were identified: the home visit as a possibility for creating links and the home visit as a possibility for integral assistance. Thus, the home visit as an instrument for health work processes - in particular in primary health attention - is a facilitating element for public health service users and also an integral way of attending them, in which the real needs of individuals and families can be identified. KEYWORDS: Home visit; Home help; Nursing in public health.

\section{LA VISITA DOMICILIAR EN LA ESTRATEGIA SALUD DE LA FAMILIA: PERCEPCIÓN DE ENFERMEROS}

RESUMEN: La visita domiciliar es, actualmente, un instrumento esencial para la práctica de las acciones en el nivel primario de asistencia a la salud, en especial, en la Estrategia Salud de la Familia. Este es un estudio descriptivo y exploratorio, de abordaje cualitativo, cuyo objetivo fue identificar y analizar la percepción de enfermeros acerca de la visita domiciliar. Para el análisis de los datos, se ha ulitizado la técnica del Análisis Temático. Fueron identificadas dos unidades temáticas: $L a$ visita domiciliar como posibilidad de creación de vínculo y La visita domiciliar como posibilidad de asistencia integral. Así, la visita domiciliar como instrumento del proceso de trabajo en salud, en especial, en la Atención Primaria a la Salud, se constituye como elemento facilitador para el acceso por parte de los usuarios a los servicios públicos de salud y se presenta como una forma integral de asistir, en que las reales necesidades de cada individuo/familia pueden ser identificadas.

PALABRAS-CLAVE: Visita domiciliar; Asistencia domiciliar; Enfermería en salud pública.

\footnotetext{
${ }^{1}$ Enfermeiro. Mestre em Enfermagem. Professor do Instituto Multidisciplinar em Saúde da Universidade Federal da Bahia. Doutorando em Enfermagem pelo Programa de Pós-Graduação em Enfermagem da Universidade Estadual de Campinas-SP.

${ }^{2}$ Enfermeira da Santa Casa de Aparecida do Taboado-MS. Pós-Graduanda em Gestão do Sistema Único de Saúde.
} 


\section{INTRODUÇÃO}

O interesse pelo tema "visita domiciliar" se deve ao fato de fazer parte da nossa atuação nos serviços de saúde, em especial, nos serviços de Atenção Primária à Saúde. Desse modo, entre as atividades desenvolvidas pelo profissional enfermeiro, chama-nos a atenção a importância da visita domiciliar na prática dos serviços da Estratégia Saúde da Família (ESF).

A ESF é uma das estratégias de governo, institucionalizada para reorganizar a prática assistencial de saúde possuindo como eixo condutor a modificação do modelo assistencial hegemônico; este modelo se caracteriza pela preocupação com a produção de procedimentos centrados no atendimento médico individual curativo, medicalizante e hospitalocêntrico. A mudança no modelo assitencial se pauta nos princípios do Sistema Único de Saúde e elege novas bases e critérios para atuação. A assistência deverá ser centrada na família, focada a partir de contexto físico e social em que vive. Assim, pressupõe o estabelecimento de vínculo, de corresponsabilidade, de desenvolvimento de autonomia entre os trabalhadores de saúde e as pessoas que vivem no território da área de abrangência de cada equipe ${ }^{(1)}$.

Esta estratégia utiliza-se, fundamentalmente, da visita domiciliar (VD), pois esta possibilita aos trabalhadores da equipe de Saúde da Família conhecer seu contexto e sua inserção em uma dada comunidade ${ }^{(2)}$. Uma prática assistencial com esses atributos necessita de uma compreensão ampliada do processo saúdedoença e de intervenções para além de procedimentos técnicos. Dentro desse desafio, a Reforma Sanitária, iniciada na década de 1970, traz para o cenário das políticas de saúde e das práticas assistenciais novas demandas e desafios que carecem ser enfrentados e construídos. A elaboração de ferramentas e sua operacionalização na produção de ações cuidadoras constituem-se num desses desafios ${ }^{(3)}$.

Neste contexto, a VD torna-se essencial para prestação de uma assistência de enfermagem que procure envolver, de fato, as ações de prevenção de doenças e de promoção da saúde. Essas ações constituem o cerne da atenção básica em saúde no Brasil.

Na ESF a VD constitui uma atividade utilizada com a finalidade de subsidiar a intervenção no processo saúdedoença de indivíduos ou o planejamento de ações almejando à promoção de saúde da coletividade, se constituindo em um instrumento essencial, utilizado pelos integrantes das equipes de saúde para conhecer as condições de vida e saúde das famílias sob sua responsabilidade ${ }^{(4)}$.
Nesse sentido, o espaço domiciliar é potente para promover a reflexão das relações usuários/trabalhadores de saúde no cenário de saúde intradomiciliar. Nos serviços de saúde, quase sempre o usuário é visto como objeto, e o trabalhador de saúde, de forma hierárquica, se coloca no topo da relação, enquanto no domicílio essa relação tende a se tornar horizontalizada e baseada por trocas de subjetividades. Assim, é necessário salientar que os espaços nos serviços de saúde são dos trabalhadores de saúde e que, nos domicílios, eles são de domínio do usuário. Diante dessas colocações, é evidente que a humanização do atendimento na prestação da assistência à saúde caracteriza-se como fator essencial para investir nessa estratégia ${ }^{(3)}$.

A VD pode ser definida como "um conjunto de ações de saúde voltadas para o atendimento tanto educativo como assistencial"(5:35). Constitui-se como uma atividade educativa e assistencial que possibilita uma interação mais efetiva entre os membros da equipe de saúde, na medida em que possibilita o convívio desta com a realidade vivenciada pelo usuário-família. Assim, a visita é um importante instrumento, o qual proporciona ao profissional o conhecimento das condições socioeconômicas, culturais e ambientais onde trabalha ${ }^{(6)}$.

A VD é importante para operacionalizar parte de um programa ou de uma política de assistência à saúde presente em uma sociedade num dado momento histórico. Neste sentido, ela é utilizada para realizar inquéritos, cadastramentos, controle de usuários faltosos, controle de focos epidêmicos; em resumo, para efetivar ações pontuais. Geralmente, essas ações são realizadas por um agente de saúde treinado, previamente, para desenvolver a atividade em foco ${ }^{(3)}$.

A assistência domiciliar, no atual cenário das políticas de saúde, especificamente no contexto do ESF, ao utilizar a VD como instrumento de trabalho, é caracterizada pelo desenvolvimento de ações de promoção, prevenção e reabilitação à saúde do indivíduo e família. Na atual conjuntura dos serviços de saúde, é necessária para prestação dessa assistência uma equipe multidisciplinar, que trabalhe com um conjunto de conhecimentos que vão além do biológico, e com uma estreita relação com a organização dos serviços de saúde, resultando disso a conformação do modelo assistencial ${ }^{(3)}$.

Diante da revisão da literatura realizada e da utilização em larga escala da ESF no contexto dos serviços públicos de saúde, especificamente na atenção básica, a VD tem sido coinsiderada um instrumento essencial para a prática de assistência a saúde por parte dos trabalhadores que constituem a equipe de Saúde da 
Família: enfermeiro, médico, técnico em enfermagem, cirurgião-dentista, auxiliar de consultório dentário e agentes comunitários de saúde. Dentre estes trabalhadores, os agentes comunitários de saúde são os que realizam a VD com maior frequência.

Na prática desses serviços, percebe-se que o planejamento das ações desenvolvidas na Unidade de Saúde da Família, ou no domicílio, fica sob a responsabilidade do profissional enfermeiro. Este realiza VD com certa frequência, no entanto, em nossa experiência, a forma como as visitas têm sido realizadas causa certa inquietação, sendo razão para que se buscasse conhecer a percepção que o profissional enfermeiro da ESF tem acerca da realização de VD.

É importante salientar que, muitas vezes, o emprego da VD está voltado aos usuários portadores de doenças crônicas, como a hipertensão arterial e o diabetes mellitus. As ações de prevenção de complicações são importantes mas, empiricamente, nota-se que a VD é mais utilizada para as ações curativas do que para as ações de prevenção de doenças e promoção da saúde, ações estas que se caracterizam como cerne dos serviços da atenção básica.

Neste contexto, foi objetivo deste estudo identificar e analisar a percepção de enfermeiros sobre a visita domiciliar da Estratégia Saúde da Família.

\section{METODOLOGIA}

Este é um estudo do tipo exploratório e descritivo, com abordagem qualitativa e foi desenvolvido nas Unidades Saúde da Família de um município do noroeste do Estado de São Paulo, o qual apresenta uma estrutura de assistência nos níveis primário e secundário. Foram sujeitos da pesquisa os enfermeiros que atenderam aos critérios de inclusão do estudo: atuar na ESF há pelo menos seis meses; realizar visitas domiciliares; concordar em participar do estudo e assinar o Termo de Consentimento Livre e Esclarecido.

Este estudo foi aprovado pelo Comitê de Ética em Pesquisa da Faculdade de Medicina de São José do Rio Preto, identificado pelo protocolo n. 3789/2008 (parecer 250/2008), conforme Resolução 196/96 que dispõe sobre as pesquisas envolvendo seres humanos.

A coleta de dados se deu por meio de entrevista gravada e cujo teor foi transcrito na íntegra e analisado por meio de análise temática, com a finalidade de descobrir os núcleos de sentido. Esses formam uma comunicação e, cuja presença ou frequência de aparição, podem trazer significados para o objetivo analítico visado. Para tanto, seguiu-se as etapas propostas ${ }^{(7)}$ : pré-análise, exploração do material, tratamento dos resultados obtidos e interpretação. A pré-análise exigiu várias leituras flutuantes das falas transcristas dos entrevistados. Após a préanálise foi feita a constituição do corpus, que consistiu na organização dos conteúdos das falas, de modo que este pudesse responder a algumas normas de validade. Finalmente, foi feita a formulação de hipótese e objetivos, em que analisamos e avaliamos os pressupostos iniciais e os emergentes relativos à temática.

\section{RESULTADOS}

Nesta pesquisa, foram entrevistadas 8 enfermeiras, cuja atuação na ESF variava de seis meses a oito anos. Três tinham curso de especialização em Enfermagem em Unidade de Terapia Intensiva, uma em Enfermagem do Trabalho e Gerenciamento de Unidades do Sistema Único de Saúde, duas em Enfermagem do Trabalho, e uma com especialização em Programa Saúde da Família, e uma estava cursando cursando especialização em Saúde Coletiva.

Após a análise sistemática dos discursos, foi possível elencar e construir duas unidades temáticas: $A$ visita domiciliar como possibilidade de criação de vínculo e $A$ visita domiciliária como possibilidade de uma assistência integral.

\section{DISCUSSÃO}

\section{A visita domiciliar como possibilidade de criação de vínculo}

As enfermeiras entrevistadas percebem a VD como uma possibilidade de criação de condições que levam a uma proximidade especial com as famílias. Assim se expressou uma delas:

[...] sem falar no vínculo que a gente cria com a família; então, qualquer problema que a família passa ter a ter, eles procuram por nós na unidade. E eles acabam falando coisas pra nós, que quando vem na unidade eles não falam. (Entrevista A)

Nesse depoimento fica evidenciado que o estabelecimento de vínculo com o usuário é uma forma de proporcionar a liberdade de relatar questões que dizem respeito a ele e à sua família, questões que provavelmente ele não abordaria sem esta proximidade com os trabalhadores da equipe de Saúde da Família. 
Bem, visita domiciliar, ela tem uma grande importância, pra gente criar um vínculo não só com ele, mas também dentro do contexto que ele vive. (Entrevista B)

Este contexto à criação de vínculos no âmbito dos serviços de saúde está diretamente relacionado com uma rede de relações sociais ${ }^{(8)}$.

Bom, pra mim, visita domiciliar significa vínculo familiar, amizade, segurança, confiança tanto da equipe do ESF como para as famílias e para as pessoas. (Entrevista C)

O mais importante, ainda, é o vinculo que a gente estabelece durante essas visitas. E quando a gente vai à casa, e a gente tem postura, ética, boa conduta, a gente consegue ter um vínculo muito grande com a familia toda, [fazer] os cuidados necessários para o individuo e pra todas as pessoas da casa. (Entrevista D)

A equipe fica vinculada com a família, não é como se fosse uma instituição, que a gente não tem contato nenhum. A pessoa vai, a gente não sabe o nome, com quem mora, ou, senão, de onde ela veio. Então, assim, a gente cria um vínculo e até é bom, porque conforme vai passar o tempo, vira família mesmo. A pessoa vem, já te conhece pelo nome, conta seus segredos. Se ele tem algum problema, se ele tem alguma dificuldade, ele se abre pra você e você pode estar tentando ajudar. (Entrevista F)

Criar vínculos envolve o estabelecimento de relações muito próximas e nítidas, em que nós nos sensibilizamos com o sofrimento do outro; é a constituição de um processo de troca entre usuário e trabalhador, tendo como cerne a construção da autonomia do usuário. O vínculo, ainda implica em se integrar com a comunidade em seu território, nos grupos, e se tornar referência para o usuário, seja no aspecto singular ou coletivo $^{(9)}$ :

Olha, em minha opinião, é de fundamental importância a visita domiciliar, porque você cria um vínculo maior com a sua comunidade. Você fica conhecendo os problemas do domicílio. (Entrevista G)

Em minha opinião, a visita domiciliar é fundamental na Estratégia Saúde da Família. Ela é de extrema importância, porque é a partir dessa visita que a gente vai criar um maior vínculo com toda a família. A gente vai poder conhecer de perto os costumes, as crenças, porque o lar é a sala da gente. Então, conhecendo a casa da pessoa, você vai poder conhecer um pouco mais sobre ela. (Entrevista $\mathrm{H}$ )

Diante das falas e da discussão teórica feita, concordamos com diferentes pesquisadores quando apontam o vínculo como possibilidade da construção da autonomia do usuário, numa relação horizontalizada entre trabalhador de saúde e usuário, em que sejam encontradas estratégias eficazes de intervenção no processo saúde-doença do indivíduo e coletividades. Quanto a isso, ainda é importante considerar que:

As diferentes formas de produção de vínculo não estabelecem ou privilegiam espaços, mas podemos considerar a VD como um momento singular na construção do mesmo, já que é durante a atividade desenvolvida no domicílio que há a real possibilidade de estabelecer responsabilidades pelo problema de saúde do usuário. Responsabilidade que passa pelo aumento da capacidade de escuta, que é feita pela aproximação maior com os problemas de saúde, em estar em um ambiente diferente dos serviços de saúde que torna possível uma reflexão mais ampla sobre o processo de nascer e morrer da comunidade ${ }^{(10: 64)}$.

Desse modo, o vínculo amplia a eficácia dos serviços de saúde e proporciona a participação do usuário durante a assistência recebida dos serviços de saúde ${ }^{(11)}$.

\section{A visita domiciliar como possibilidade de uma as- sistência integral}

Nas falas das entrevistadas, outro aspecto importante que emergiu foi a percepção da VD como possibilidade de assistência integral ao usuário/família.

No contexto dos serviços de saúde há muitos modos de se conceituar e compreender a integralidade. A própria Constituição da República Federativa do Brasil, ao apontar a integralidade, tece uma crítica no sentido de refletir sobre as práticas preventivas e curativas como práticas dicotômicas. Afirma ainda que as ações preventivas devem ser priorizadas sem prejuízo das ações de assistência. Desse modo, os usuários do SUS têm garantido o seu direito a uma assistência em qualquer que seja o nível de complexidade do sistema, o que é determinado por sua real necessidade de saúde ${ }^{(12)}$. Para essa avaliação a VD é um importante mediador:

É muito importante essa visita, porque lá no contato dentro da casa, o paciente ali, de repente, relata 
alguma coisa que vai ser muito importante para o tratamento. Dependendo de cada caso que for, ou seja, hipertenso, diabético, ou mesmo uma visita de rotina, a gente visualiza dentro da casa as condições de higiene, os hábitos alimentares, como está o quintal, porque a gente se preocupa em relação às doenças que existem, como a dengue. A gente tem problema de esquistossomose nos animais. Então assim, na verdade essa visita a gente vê, analisa a pessoa como um todo dentro do seu estado geral de saúde e também no ambiente familiar, como ele é. (Entrevista D)

Nos discursos fica evidente uma segunda forma de conceituar e compreender a integralidade, e que seria uma forma de romper com o modelo tradicional hegemônico de assistência à saúde, centrado num reducionismo biomédico. Assim:

[...] a integralidade busca a compreensão das dimensões que determinam a produção da saúde e da doença, envolvendo o sujeito como um todo e suas relações com a sociedade e o meio ambiente e não apenas, sua descrição biológica ${ }^{(12: 71)}$.

Seguindo esta forma de entendimento, fica evidente que a VD é parte inerente do processo de trabalho voltado a grupos específicos da população. Logo, esta também pode ser compreendida como outra modalidade de entender a integralidade, de forma que:

[...] as políticas de saúde constituídas em cima dos parâmetros da integralidade, permitem aos portadores de uma doença o acesso às ações de assistência que necessitam e os não portadores da mesma, se beneficiam das ações preventivas. Pode-se perceber que o princípio da integralidade só é possível através de um olhar atento, que possibilite apreender as necessidades das ações levando em conta a contextualização. Na perspectiva deste princípio não podemos reduzir o sujeito à doença que lhe provoca sofrimento, e sim buscar uma atenção voltada à idéia de totalidade do sujeito ${ }^{(13: 533)}$.

Os seguintes depoimentos referendam esses aspectos:

Olha, a visita em enfermagem para uma familia é importante, porque lá você consegue ver realmente qual é a necessidade daquela família, como está sendo cuidada a casa, se tem higienização, se não tem, ou como está o quintal. Lá, quando você está no ambiente deles [os usuários], eles acabam contando sobre os problemas. Às vezes, tem coisas que eles não têm coragem de dizer para o médico ou para o agente comunitário. Então, para a enfermeira eles acabam confiando mais e você consegue descobrir muito mais coisas que, às vezes, as pessoas não conseguiam. Até mesmo no caso da vacinação, que a gente encontra muita resistência, se a enfermeira vai à casa, conversa com aquele paciente, ele acaba cedendo a você, [e se] consegue atingir a meta que é a vacinação. (Entrevista E)

Com a visita domiciliar a gente pode estar indo nas casas conhecer a realidade que ele [o usuário] vive e a família, se ele tem algum problema social, psicológico. E só na visita, mesmo, que a gente pode estar tendo esse conhecimento. As visitas que a gente faz aqui na unidade, a gente consegue acompanhar o paciente que o agente comunitário traz, os casos que ele consegue no seu dia a dia, nas suas visitas também. E depois que a gente avalia e aí passa na casa do paciente, aí a gente vê a necessidade e a possibilidade de estar passando para um outro profissional, porque a gente lida com uma equipe muito disciplinar. Então, se eu tenho algum problema, o médico pode estar atendendo. Assistência social, nutricionista, porque na nossa cidade tem esse andamento nas visitas. Se tem algum problema, a gente passa para outras esferas até se resolver. (Entrevista F)

Portanto, a VD apresenta vantagens trazidas pela aproximação com o meio ambiente do grupo familiar, facilitando o planejamento das ações de saúde. Ela aproxima por ser menos formal; possibilita também maior liberdade para conversar sobre as reais necessidades de saúde. No entanto, não podemos esquecer que a VD traz consigo questões importantes que devem ser tratadas com muita delicadeza pela equipe de Saúde da Família. Entre estas, a interrupção de tarefas domésticas, a necessidade de reconhecimento do limite entre uma ação de mera sociabilidade e as ações de saúde, ressaltando que a entrada no domicílio deve considerar algumas regras básicas, no sentido de estabelecer o limite tênue entre o controle excessivo e a liberdade exacerbada ${ }^{(10)}$.

A VD, empregada no âmbito dos serviços de saúde, não se caracteriza como atividade meramente social; ela tem objetivos específicos, sendo uma ação desenvolvida por profissionais de saúde que pode ser alterada de acordo com a avaliação feita durante a atividade ${ }^{(10)}$.

Numa pesquisa, em que o objetivo foi estudar a visão dos usuários acerca da $\mathrm{VD}$, identificou-se que estes a percebem como possibilidade de acesso aos serviços de saúde, como suporte social às famílias, sendo ainda ressaltados o trabalho da equipe e as ações desenvolvidas no ambiente domiciliar ${ }^{(14)}$. 


\section{CONSIDERAÇÕES FINAIS}

A VD desponta como importante elemento dentro do processo de trabalho em saúde na ESF, em particular na Atenção Primária à Saúde em que o domicílio se torna um espaço público, com a presença dos trabalhadores de saúde.

Mesmo o cenário domiciliar se caracterizando como espaço de atuação e contexto de assistência ao usuário/família, se os atores sociais envolvidos neste processo (trabalhadores de saúde - usuários) estabelecerem uma relação horizontalizada e com o estabelecimento de vínculo, esta poderá ser uma forma de desenvolver a assistência de forma integral.

A VD tem sido discutida nos cursos de graduação em Enfermagem, porém, cabe aqui destacar a importância da discussão dessa temática, como se dá a operacionalização da mesma, permitindo refletir acerca da possibilidade de assistir a família de forma integral.

Neste contexto, percebemos, por meio da prática clínica, que em algumas situações a VD acontece de forma mecanizada e sem o entendimento do valioso instrumento que ela pode se constituir no processo de trabalho em saúde e, em particular, nos serviços do nível primário de assistência à saúde.

Acreditamos que esta pesquisa contribuirá para o desenvolvimento harmônico das ações de prevenção de doenças, de promoção da saúde, além das atividades curativas e de reabilitação, proporcionando um atendimento específico, diferenciado e eficaz para todos os usuários da ESF, tanto do município do estudo como em outros serviços de saúde do Brasil.

\section{REFERÊNCIAS}

1. Ministério da Saúde (BR). Saúde da família: uma estratégia para reorientação do modelo assistencial. Brasília: Ministério da Saúde; 1998.

2. Giacomazzi CM, Lacerda MR. A prática da assistência domiciliar dos profissionais da estratégia saúde da família. Texto \& Contexto Enferm. 2006;15(4):645-53.

3. Pereira MJB, Mishima SM, Fortuna CM, Matumoto S, Teixeira RA, Ferraz CA, et al. Assistência domiciliar: instrumento para potencializar processos de trabalho na assistência e formação. In: Ministério da Saúde (BR). Observatório de recursos humanos em saúde no Brasil: estudos e análise. Rio de Janeiro: Fiocruz; 2004. v. 2. p. 71-80.

4. Takahashi RF, Oliveira MAC. A visita domiciliária no contexto da saúde da família. In: Brasil IDS. Manual de enfermagem. Brasília: Ministério da Saúde, 2001. p. 43-6.
5. Mattos TM. Visita domiciliária. In: Kawamoto EE, Santos MCH, Mattos TM. Enfermagem comunitária. São Paulo: Editora Pedagógica e Universitária; 1995. p. 35-9.

6. Padilha MICS, Carvalho MTC, Silva MO, Pinto VT. Visita domiciliar: uma alternativa assistencial. Rev Enferm UERJ. 1994;2(1):83-90.

7. Minayo MCS. O desafio do conhecimento: pesquisa qualitativa em saúde. $4^{\mathrm{a}}$ ed. São Paulo: Hucitec; 2004.

8. Víctora CG, Knauth DR, Hassen MNA. Pesquisa qualitativa em saúde: uma introdução ao tema. Porto Alegre: Tomo; 2000.

9. Merhy EE. Em busca da qualidade de serviços de saúde: os serviços de porta aberta para a saúde e o modelo tecnoassistencial em defesa da vida. In: Cecílio LC, Merhy EE, Campos GWS. Inventando a mudança na saúde. São Paulo: Hucitec; 1994.

10. Abrahão AL, Lagrange V. A visita domiciliar como uma estratégia da assistência no domicílio. In: Morosini MVGC, organizador. Modelos de atenção e a saúde da família. Rio de Janeiro: EPSJV/Fiocruz; 2007. p. 151-72.

11. Schimith MD, Lima MADS. Acolhimento e vínculo em uma equipe do programa saúde da família. Cad Saude Publica. 2004;20(6):1487-94.

12. Matta GC. Princípios e diretrizes do sistema único de saúde. In: Matta GC. Políticas de saúde: organização e operacionalização do sistema único de saúde. Rio de Janeiro: EPSJV/Fiocruz; 2007. p. 61-80.

13. Fontoura RT, Mayer CN. Uma breve reflexão sobre a integralidade. Rev Bras Enferm. 2006;59(4):532-7.

14. Santos EM. A visita domiciliária sob a ótica dos usuários da estratégia saúde da família [dissertação]. Campinas (SP): Universidade Estadual de Campinas; 2008. 